\title{
“A DANÇA DA DESTRUIÇÃO”: MELANCOLIA E FANTASMAGORIA EM OS ANÉIS DE SATURNO
}

\section{Carla Lavorati $^{1}$}

Resumo: O objetivo deste estudo é refletir sobre a narrativa de Os Anéis de Saturno, de W. G Sebald, para observar como é trabalhada a imagem fantasmática e o tom melancólico na tessitura do texto, pois o narrador assume uma postura desesperançosa ao recuperar, do presente, vestígios da destruição ocorrida no passado. Narrador que observa, recorda, seleciona, faz inferências, pensa e se posiciona de modo crítico diante dos rumos do "progresso" e do desenrolar da história da humanidade. E que transfigura suas investigações e conhecimentos, de modo fantasmático, em representação literária, buscando pelo tensionamento das fronteiras entre o real e 0 imaginário, "recuperar", numa postura ética, fragmentos do passado que jaziam sem sentido - se observados pelo olhar desmemoriado e alienante do século XXI - relacionando-os com a história da civilização.

Palavras-chave: ruínas, melancolia, fantasmagoria.

\begin{abstract}
The aim of this study is to reflect on the narrative Os Anéis de Saturno, of G W. Sebald, to observe how ghostly image and melancholy is configured in the tessitura of the text, as the narrator takes on a hopeless position to recover, from the present, vestiges of destruction that occurred in the past. The narrator observes, recalls, selects, makes inferences, thinks and stands critically on the course of "progress" and the unfolding of human history. And that turns their research and knowledge in a ghostly way in literary representation, seeking the tension of the boundaries between the real and the imaginary, "recover" in an ethical stance, fragments of the past that lay senseless - if observed through the amnesiac and alienating look of the twentyfirst century - relating them to the history of civilization.
\end{abstract}

Keywords: ruins, melancholy, phantasmagoria.

Facilmente aceitamos a realidade, talvez por intuirmos que nada é real. Sonhei a dúvida e a certeza. (Jorge Luis Borges)

\footnotetext{
${ }^{1}$ Doutoranda no Programa de Pós-Graduação em Letras, Estudos Literários, da Universidade Federal de Santa Maria. Bolsista Capes. Integrante da linha de pesquisa "Literatura, Comparatismo e Crítica Social" e do grupo de estudos "Literatura e Autoritarismo", sob orientação da professora Dra. Rosani Ketzer Umbach. E-mail: ca_lavorati@yahoo.com.br
} 


\section{Introdução}

A narrativa de Os Anéis de Saturno de W. G Sebald é de difícil definição. Construída na fronteira dos gêneros, sua forma mescla: ensaio, autobiografia, memorialismo, relato de viagem, ficção... É uma narrativa que estrutura-se numa combinação entre o peso corpóreo do conhecimento enciclopédico acionado pelo narrador intelectualizado e a "leveza" do próprio espaço de criação da narrativa, que é o espaço literário, lugar comum a inventividade e aos desdobramentos da imaginação. Em Os Anéis de Saturno, encontramos, portanto, transfigurado em material estético, toda uma carga de conhecimento racional (pesquisas, reflexões, observações sobre o universo, o mundo, 0 homem), coisas mínimas ou gigantescas, reais e imaginadas, enredadas ou destinadas a se enredar, pelo inevitável processo de destruição, seja ele ato racional e planejado ou mesmo fatalidade do incontrolável e incontornável.

Desse certo modo, percebemos em Os Anéis de Saturno que o enredo é sustentado pelo processo infinito de pensamento, das idéias e formas que levam a outras formas, do fragmento que se abre, enquanto potencialidade de sentido, para outro fragmento, histórias, ruínas; formando associações curiosas e inquietantes, "amarradas" pelo fio de Ariadne, que são as destruições relacionadas às guerras. $O$ que conduz, em alguns momentos, a questionamentos sobre o absurdo da realidade e do projeto civilizatório; um grotesco da "realidade", que provocam um sorriso amarelo, um frio na espinha do leitor, que de alguma forma compreende a limitação do sujeito diante do obscuro e desconhecido, do que escapa da razão, do próprio aspecto desumano do humano levado ao extremo pela banalidade do mal. A obra pode ser pensada como um romance de idéias, aonde a própria sustentação do conteúdo advém continuidade do pensamento, das relações estabelecidas pelo autor no caminhar vagaroso e solitário que empreende para reunir as histórias pessoais (reais e fictícias) e dos objetos, natureza à história coletiva da humanidade, num processo baseado na memória e consciência ética do narrador. 
E nesse sentido, a narrativa de Os Anéis de Saturno, de certo modo, oferece resposta às possibilidades narrativas pós auschwitz, posicionando-se de modo ético diante da memória histórica dos fatos, sem, no entanto, subscrever os discursos do holocausto; ao mesmo tempo que sua estrutura formal se constrói no movimento contrário ao indivíduo desmemoriado, imediatista e eufórico do XXI. Mesmo com essa postura crítica e esse tom consciente, e talvez justamente por isso, na narrativa de Anéis de Saturno o narrador reflete também sobre os limites do conhecimento, sobre 0 inapreensível, que mesmo com todo o avanço da ciência e da técnica não deixou de "assombrar-nos", posto que desvela nossa própria incompletude e fragilidade enquanto ser. Encontramos essa consciência manifestada pelo narrador quando relata que vê pela janela do quarto de hospital uma "risca de vapor" cortar o céu, e que interpretando a princípio como algo positivo, considera posteriormente a marca do início de uma fissura que vai acompanhálo durante toda a vida; que é "A invisibilidade e intangibilidade daquilo que nos move [...] um mistério insondável [...] que via nosso mundo somente como sombra de um outro mundo" (SEBALD, 2010, p. 27), uma imagem ligada a essa espécie de impotência e de nebulismo, incomensurável que nos atinge e que faz parte da incompletude do ser.

Nesse sentido, o objetivo é observar, como em Anéis de Saturno, o narrador, por meio de operações fantasmáticas e postura melancólica, constrói uma narrativa esteticamente elaborada e consciente dos desdobramentos negativos da história da humanidade, do sentimento de incapacidade que nos toma quanto olhamos para as ruínas do passado, para os escombros e destruição que ficaram pelo caminho, para os absurdos do racionalismo e da burocracia alienante que contribuíram com as catástrofes do século $X X$. Superando a imobilidade das asas abertas de Angelus Novus, de Paul Klee, que o impede de voltar ao passado para "resgatar" os escombros, o narrador de Sebald, empreende a observação de passado no presente, mas sem se livrar dos sentimentos melancólicos, que seu olhar para os vestígios da destruição, provoca. O narrador não sai ileso das próprias reminiscências, atingido que é pela imobilidade no final de sua viagem, figurando metaforicamente a simbologia da melancolia presente na pintura de Durer. É uma narrativa, nesse sentido, ética, pois é consciente da importância da |8| Revista Eletrônica Literatura e Autoritarismo, № 26 - julho a dezembro de 2015 - ISSN 1679-849X http://cascavel.ufsm.br/revistas/ojs-2.2.2/index.php/LA/index 
memória e da incorporação da ficção de temas caros a história, que contribuam para reflexão e questionamentos do próprio limite da razão e do humano, num cuidado estético, de não sub escrever as narrativas testemunhais do período. Mais do que isso, produz uma narrativa de grande potencial simbólico que oferece ao leitor "chaves" associativas que conduzem o pensamento por cadeias de significados que tiram do empobrecimento de sentido os fragmentos do passado. Portanto, a análise de Os Anéis de Saturno, que empreendemos nesse artigo, considera a narrativa, como resultado da transfiguração em linguagem das imagens fantasmáticas impressas na memória e advindas das experiências vividas pelo autor-narrador ${ }^{2}$, um andarilho intelectual, que reflete em suas impressões e relatos o mal estar e a melancolia, provocados pelo constante presença da destruição que observa em suas andanças.

\section{Melancolia e Fantasmagoria em Anéis de Saturno}

Como uma dança da destruição que se assemelha ao movimento dos "anéis de saturno", espécie de metáfora para o contínuo e inevitável processo da destruição e/ou transformação de uma coisa em outra; fragmentos do passado são "recuperados" pelo narrador, a passos lentos, e trazidos de alguma forma pelas voltas imaginativas do pensamento, ao presente, num movimento que rompe com o esquecimento. Os pares dessa dança pungente são objetos, histórias pessoais (reais e fictícias), a natureza e a própria arquitetura que "recupera" sentidos e os coloca em movimento por meio de diferentes camadas de significação.

O tom ensaístico encontrado em Os Anéis de Saturno, processo presente durante toda a narrativa e que se desdobra na cadeia de associações por semelhança - o que une a pesca do arenque ao vazio existencial dos pescadores - é o que dá "corpo" ao romance e mantém uma confluência

\footnotetext{
${ }^{2}$ É interessante observar que o narrador de Os Anéis de Saturno é uma espécie de duplo, de dobra fantasmática do próprio autor Sebald, o que traz a possibilidade de repensar as relações de autoria na contemporaneidade, após as discussões correntes que defendiam a "morte" do autor e o "renascimento" do leitor.
} 
harmônica entre "filosofia" e "poesia", entre pensamento crítico e criação ${ }^{3}$, tal qual o narrador comenta sobre o modo de pensar e de escrever de Tomas Browne, "[...] ele tentava sempre considerar a existência terrena, as coisas que Ihe eram mais próximas como também as esferas do universo, da perspectiva de um forasteiro, ou poderíamos dizer, com o olho do criador" (SEBALD, 2010. p. 28). É, portanto, um narrador observar do presente, um "colecionador" de memórias, que se movimenta e estabelece observações, e que ao pensar nos detalhes e nas coisas mínimas - tal qual Flaubert que é capaz de ver o deserto num grão de areia - também, compreende e empreende ligações entre o que há de mais "insignificante" e o universo inteiro. Desse modo, mesmo por meio da utilização de uma linguagem objetiva e racional, não deixa de considerar as possibilidades da imaginação, consciente que é da própria impossibilidade de apreensão da realidade em absoluto e dos riscos da linguagem como representação fiel do real.

O narrador pode ser considerado um alter ego do próprio autor, pois a narrativa parte de experiências vividas por W. G Sebald em agosto de 1992, que empreende uma viagem a pé pela costa leste da Inglaterra, tal qual o narrador. Nesse movimento de quem caminha e observa o seu entorno, buscando nos detalhes os resquícios do passado e os sentidos outros "esquecidos" nesses objetos, a narrativa se estrutura na contramão da velocidade que predomina na cultura ocidental do mundo capitalista e globalizado, pois a demora do caminhar é o que permite o olhar observador e contemplativo do narrador que constrói suas experiências, seu pensar e suas reflexões, na contramão da alienação e do desmemoralismo da atualidade. As narrativas de W. G Sebald, de modo geral, oferecem aspectos interessantes

\footnotetext{
${ }^{3}$ O que por sua vez, nos remete ao prefácio do livro Estâncias de Giorge Agamben, aonde o autor retoma a cisão que separou filosofia e poesia, e reflete sobre como essa separação está consolidada no próprio modo de pensar ocidental; "A cisão entre poesia e filosofia testemunha a impossibilidade da cultura ocidental de possuir plenamente o objeto do conhecimento (pois o problema do conhecimento é um problema de posse, e todo problema de posse é um problema de gozo, ou seja, de linguagem)" (AGAMBEN, 2007, p. 12). Nesse caso, como sugere Agamben, o conhecimento em nossa cultura está "cindido" entre o que é racional e, portanto consciente, e o que é inspiração, "O que dessa forma acaba sendo suprimido é que toda autêntica intenção poética se volta para o conhecimento, assim como todo verdadeiro filosofar está sempre voltado para a alegria" (AGAMBEN, 2007, p. 13). De certa forma, observamos a narrativa de Anéis de Saturno como uma confluência enriquecedora entre ficção e pensamento filosófico.
} 
para observações sobre os rumos tomados pela literatura, as novas perspectivas aplicadas ao narrador, autor, enredo, e forma.

Os Anéis de Saturno começa com a hospitalização do narrador, que afetado pelo horror visto em sua última viagem a pé é "[...] levado em um estado de total imobilidade ao hospital de Noerwich" (SEBALD, 2010, p. 14). Essa imobilidade que ligamos a temperamento melancólico do narrador, que tomado pela desilusão, pela tristeza, pelo encontro, a cada passo, com níveis diferentes de destruição, o faz tomar consciência que "Basta uma fração de segundo [...] e toda uma era passa." (SEBALD, 2010, p. 41), o que pode atingir até mesmo a linguagem, a palavra escrita, que não está ilesa as possibilidades de desaparecimento, pois "Em cada nova forma já reside a sombra da destruição. É que a história do indivíduo, de cada sociedade e do mundo inteiro não descreve um arco que se expande cada vez mais e ganha em beleza, mas uma órbita que, uma vez atingido o meridiano, declina rumo às trevas" (SEBALD, 2010, p. 32). Mas a melancolia também pode ser observada por uma perspectiva positiva, pois está ligada ao próprio movimento contemplativo e crítico do autor, assemelhando-se aos aspectos da criação, da ligação com a arte e a reflexão, tal qual citado por Agamben (2007) ao retomar Aristóteles e sugerir ligações positivas entre melancolia e gênio criativo, como também ressaltando os benefícios da atitude contemplativa contida em algumas reflexões patrísticas sobre o termo acídia ${ }^{4}$, na Idade Média, que considerava "[...] a idéia de um risco mortal inscrito na mais nobre das intenções humanas ou de uma possibilidade de salvação escondida no perigo mais extremo" (AGAMBEN, 2007, p. 38). Na atualidade, podemos associar à postura melancólica a angústia do passar do tempo, a sensação de que não estamos caminhando no rumo certo, a consciência que somos e seremos sempre

\footnotetext{
${ }^{4}$ Segundo Agamben (2007) se examinarmos a interpretação que os doutores da Igreja dão sobre o que é acídia notamos que ela não é posta sob o signo da preguiça, mas sim da angústia, tristeza e do desespero. A acídia foi representada pela iconografia medieval como "[...] uma mulher que desoladamente deixa cair por terra o olhar e solta a cabeça sustentada pela mão, ou então como um burguês ou um religioso que confia o próprio desconforto ao travesseiro que o diabo lhe oferece (p. 30), num movimento de aprofundar-se no abismo que se abre entre o desejo e o seu inapreensível objeto, portanto, não o sono culpado do preguiçoso, mas o gesto de paralisia e desânimo diante da sua situação sem saída. A avaliação negativa que predominou na interpretação da acídia deve-se ao mal entendido que a relaciona com a preguiça e com o demônio meridiano, o somnus meridianus. Desse modo, para Agamben (2007), Panofsky e Saxl, ao investigaram a genealogia da melancolia entendem mal a concepção medieval de acídia. A sonolência é apenas uma das conseqüências da acídia e não caracteriza de modo algum sua essência, por isso o gesto da cabeça apoiada na mãe significa desespero e não sono.
} 
incompletos, e que inevitavelmente, o obscuro, o intangível faz parte de nossa complexa e efêmera existência; "E como a pedra mais pesada da melancolia é a angústia do fim inelutável de nossa natureza, Browne procura entre aquilo que escapou à aniquilação os vestígios da misteriosa capacidade de transmigração que observou tantas vezes em lagartas e mariposas." (SEBALD, 2010, p. 35). Nesse sentido, a melancolia, pode ser entendida como resultado da inevitável finitude da existência, mas também, pela tristeza em constatar o mal que a humanidade não conseguiu evitar, manifestado pelo estranhamento do narrador diante da violência, pela empatia em relação às vítimas. Nesse sentido, a melancolia torna-se elemento estético de grande potencial simbólico e mesmo que a memória do narrador não garanta acessibilidade absoluta ao que está perdido, ao menos torna possível, a incorporação de facetas fantasmáticas dessas perdas ${ }^{5}$, produzindo sentidos diferentes do senso comum.

Dado que o recesso do acídio não nasce de um defeito, mas de excitada exarcebação do desejo, que torna inacessível o próprio objeto na desesperada tentativa de proteger-se dessa forma em relação à perda e de aderir a ele pelo menos na sua ausência, assim se poderia dizer que a retratação da libido melancólica não visa senão tornar possível uma apropriação em uma situação em que posse alguma é, realmente, possível. Sob essa perspectiva, a melancolia não seria tanto a reação regressiva diante da perda do objeto do amor, quanto a capacidade fantasmática de fazer aparecer como perdido um objeto inapreensível (AGAMBEN, 2007, p. 44-45)

Dessa forma, a melancolia é experimentada pelo narrador-autor no caminhar labiríntico entre paisagens devastadas, cidades e comércios em declínio, pelo olhar observador que procura compreender o desconhecido no mundo e dentro de si mesmo, olhar atento para o que está "escondido", esquecido "embaixo" dos objetos, dos fatos e das histórias de cada lugar visitado. E nesse aspecto, é uma narrativa que constrói pela sua própria forma estilística lenta, digressiva e memorialista um movimento contrário a perda e a dissolução comum no contexto da modernidade.

\footnotetext{
${ }^{5}$ E, nesse sentindo, retomando o texto Luto e Melancolia de Freud, Agamben (2007), fala sobre o embaraço de Freud diante da constatação que diferente do luto, onde algo é realmente perdido, a melancolia não apresenta clareza do que foi perdido, e nem mesmo sabemos se realmente alguma coisa foi perdida.
}

|12 Revista Eletrônica Literatura e Autoritarismo, no 26 - julho a dezembro de 2015 - ISSN 1679-849X http://cascavel.ufsm.br/revistas/ojs-2.2.2/index.php/LA/index 
$\mathrm{Na}$ narrativa de Os Anéis de Saturno, a cada passo do narrador andarilho, o que vemos é uma contínua destruição que atinge e sempre atingirá a todos: homens, animais, objetos, natureza... Até mesmo o tempo envelhece sugere o narrador, ao citar Thomas Browne, e o que resta ao narrador é por meio da melancolia e dos processos fantasmáticos apreender, mesmo que por um instante, uma possível faceta do que está perdido. É com esse olhar, na perspectiva de "reviver" de algum modo os fragmentos do passado no presente, que o narrador estabelece operações fantasmáticas, ao transfigurar objetos, lugares e histórias pessoais, tal qual o excerto que sugere; "and so it is time to close the five ports of knowledge. We are unwilling to spin out our waking thoughts into the phantasms of sleep, marking cables of cobwebs and wildernesses of handsome groves." (SEBALD, 2010, p. 30), trabalhando a fantasmagoria enquanto produto do pensamento e da imaginação, enquanto operação inerente ao próprio processo de representação.

Nessa altura, torna-se compreensível a ambição específica do
ambíguo projeto melancólico, que a analogia com o mecanismo
exemplar do luto havia desfigurado parcialmente e tornado
irreconhecível, e que justamente a antiga teoria humoral
identificava na vontade de transformar em objeto de abraço o
que teria podido ser apenas objeto de contemplação. Cobrindo
o seu objeto com os efeitos fúnebres do luto, a melancolia lhe
confere a fantasmagórica realidade do perdido; mas enquanto
ela é o luto por um objeto inapreensível, a sua estratégia abre
um espaço à existência do irreal e delimita um cenário em que
o eu pode entrar em relação com ele, tentando uma
apropriação que posse alguma poderia igualar e perda alguma
poderia ameaçar. Se isso for verdade, se a melancolia
conseguir apropriar-se do próprio objeto só na medida em que
afirma a sua perda, compreender-se-a então porque Freud
ficou tão impressionado pela ambivalência da intenção
melancólica, a ponto de a transformar em uma de suas
características essenciais. (AGAMBEN, 2007, p. 45)

E talvez nesse sentido, que mesmo por meio de um discurso objetivo e racional, o narrador consegue, nas possibilidades criativas do campo ficcional, produzir um movimento do irracional na própria racionalidade, movendo-se, para os absurdos que compõem nossa existência.

Nesse sentido, o personagem Thomas Browne, traz informações e movimenta sentidos interessantes para a compreensão da própria narrativa de Sebald. Ambos são marcados por questionamentos que excedem os limites da 
razão, e de certo modo, buscam "A invisibilidade e a intangibilidade daquilo que nos move (...) que via nosso mundo somente como a sombra de um outro mundo." (SEBALD, 2010, p. 27-28). Um olhar que é lançado sobre o mundo, tanto para as existências terrenas como para além delas, para as esferas mais distantes, para o universo e para os mistérios que a realidade abriga e que a racionalidade não dá conta de explicar. Essa semelhança que a própria análise dos escritos de Browne estabelece com a própria totalidade de sentidos movimentados em Os Anéis de Saturno, pode ser mais bem pontuada pela observação sobre Browne a respeito da escuridão impenetrável que cerca todo conhecimento, o que, em certa medida é o tom que perpassa toda a narrativa, observe; "O que percebemos são apenas luzes isoladas no abismo da ignorância, no edifício do mundo imerso em sombras profundas. Estudamos a ordem das coisas, mas o que está por trás dela, diz Browne, nos escapa." (SEBALD, 2010, p. 28). É esse o tom, de uma racionalidade insuficiente, que percorre todo o texto de Anéis de Saturno, deixando "transparecer" por meio de fraturas da própria linguagem, a impossibilidade da compreensão integral e segura da realidade, um tom que apesar de emanar de uma linguagem construída de modo objetivo e realista, como faz Sebald, consegue que outros sentidos possíveis venham à tona, que por sua vez, produzam arranjos de significação que colocam em perspectiva as limitações da própria racionalidade que instrumentalizou o homem e a natureza. Para reforçar as semelhanças entre o personagem Thomas Browne e, de certo modo, e o tema da destruição recorrente em Os Anéis de Saturno, ressaltamos o seguinte excerto; "De forma análoga a esse contínuo processo de consumir e ser consumido, na visão de Thomas Browne também nada subsiste. Em cada nova forma já reside à sombra da destruição" (SEBALD, 2010, p. 32-33).

Para além das identificações "temáticas" entre as reflexões filosóficas de ambos os escritores, temos também como argumento, que guardadas as devidas proporções, o resultado estilístico final das escrituras de Thomas Browne e de W. G Sebald, aproximam-se, mesmo com todos os séculos que a separam. Isso pode ser observado na própria reflexão conduzida pelo narrador do livro; 
Tal como outros escritores de século XVII inglês, Browne ostenta sempre toda sua erudição, um imenso tesouro de citações e os nomes de todas as autoridades que 0 precederam, trabalhando com metáforas e analogias de vasto alcance e construindo frases labirínticas, que as vezes se estendem por uma ou duas páginas, semelhantes a procissões ou cortejos fúnebres em sua pura prodigalidade. É claro que nem sempre consegue alçar-se do chão, entre outras coisas por causa desse peso enorme que carrega, mas quando sobre cada vez mais alto, com carga e tudo, nos círculos de sua prosa, sustentando como um planador nas correntes de ar quente, então mesmo o leitor de hoje é tomado por uma sensação de estar levitando. Quanto maior a distância, mais clara a vista. Observam-se os mínimos detalhes com máxima nitidez. (SEBALD, 2010, p. 27-28)

O estilo de escrever de W. G Sebald em muitos pontos tocam as descrições sobre a própria escrita de Thomas Browne; escrita errante que é conduzida pelo movimento do pensamento e pela associação aleatória de idéias e impressões que são organizadas em frases e parágrafos longos, de linguagem objetiva e clara, mas que, mesmo diante da objetivação que empreende ao observar o mundo, mantém atenção para as dimensões subjetivas da própria percepção, e assim conseguem alçar vôo, mesmo com todo o "peso" da linguagem racional, objetiva e clara, tal qual julga o narrador de Os Anéis de Saturno acontecer à escrita de Browne. No entanto, o narrador não deixa de questionar a própria objetividade do conhecimento e aos problemas de representação da própria linguagem. Dessa forma, encontramos uma mistura da objetividade da escrita com a presença subjetiva do processo criativo, que aparece de modo mais nítido quando o narrador faz incursões na esfera dos sonhos, da imaginação, do delírio, da névoa; impressões fantasmáticas que marcam a esfera do intelecto, despertadas no narrador pelas qualidades sensíveis dos objetos, com a ressalva que a subjetividade presente em Os Anéis de Saturno, não cai no reducionismo, de acreditar que ela sozinha garanta acesso ao real. Portanto, é uma história sem arroubos, sem clímax e desfecho comum aos romances tradicionais. Apoiada na linguagem objetiva e na experiência do narrador, a textura do texto ficcional não deixa evidente a fronteira entre o real e o imaginário, pois o estético está contaminado pela linguagem do melancólico, uma reação ao estado geral de 
perda. A melancolia, nesse sentido, assume uma nova postura de conhecimento da realidade externa e de si mesmo.

E devido a essa contínua busca pela apreensão das destruições do passado que pensamos na ligação estabelecida entre o narrador, os objetos, pessoas, histórias, arquitetura, espaço, como relações de representação fantasmática, no sentido amplo de fantasmagoria como imagens produzidas no interior da mente e que deriva das impressões sensíveis da realidade, mas que não tem consistência do objeto real por ser apenas abstrações, e que mantém, portanto, a mente separada dos objetos concretos. Fantasmas que são sempre espectros, a sombra do real, construção necessário da própria percepção, condição de conhecimento e também limites do próprio conhecimento. $E$ nesse sentido em específico, liga-se o próprio processo fantasmático ao movimento de criação nas artes, tal qual exemplifica Agamben (2007) ao retomar os pintores que se tornavam melancólicos porque querendo eles manter os fantasmas presos no intelecto, para compor com maior precisão sua arte, tornam-se melancólicos.

Agamben (2007) reforça que Freud não elaborou em nenhum dos seus escritos uma teoria do fantasma, portanto, não definiu o papel deles na postura melancólica, mas faz uma leitura da melancolia (onde também estão envolvidos os processos fantasmáticos) pela inserção da problemática do libido, na sua relação com o recesso do objeto e a conseqüente retração em si mesma da intenção contemplativa; pois "A influência dessa concepção [medieval], que vinculava indissoluvelmente o temperamento saturnino à convivência com o fantasma [...] quatro séculos antes da psicanálise, já lançava as bases de uma teoria da arte entendida como operação fantasmática" (p. 52). Segundo Agamben (2007) Freud recupera o recesso do objeto e a intenção contemplativa das descrições patrísticas de acídia, mas insere na compreensão que faz da melancolia as características do luto, fazendo a ressalva que a melancolia não deixa claro o objeto perdido e nem se houve alguma perda. Segundo Agamben (2007) é importante voltar a atenção para a teoria medieval do fantasma e sua ligação com "[...] a síndrome do humor negro intimamente vinculada a uma hipertrofia mórbida da faculdade fantástica" (AGAMBEN, 2007, p. 49) para entender melhor seu sentido, e portanto, as ligações entre "[...]a teoria da imaginação, de origem aristotélica, |16| Revista Eletrônica Literatura e Autoritarismo, no 26 - julho a dezembro de 2015 - ISSN 1679-849X http://cascavel.ufsm.br/revistas/ojs-2.2.2/index.php/LA/index 
com a doutrina platônica do pneuma como veículo da alma, a teoria mágica da fascinação e aquela médica, das influências entre espírito e corpo" (AGAMBEN, 2007, p. 50). Dessa forma, a melancolia liga-se a fantasmática realidade do objeto inapreensível e não a reação regressiva da perda do objeto do amor, mas a capacidade fantasmática de fazer parecer perdido o objeto inapreensível.

$E$, pensando pela perspectiva do inapreensível e não da perda real do objeto, Agamben (2007) volta às ligações da melancolia com a teoria humoral que também entendia a melancolia como "[...] a vontade de transformar em objeto de abraço o que pode ser apenas objeto de contemplação" (AGAMBEN, 2007, p. 45). Esse processo fantasmático pode ser observado na própria estrutura do texto pelo uso de figuras de linguagem como metáfora, sinédoque e metonímia, que funcionam de certo modo como uma forma de apreender o inapreensível, representar o irrepresentável. E nesse sentido, as próprias fotografias funcionam como metáforas significando, muitas vezes, uma coisa pela outra.

Portanto, nota-se que num processo de essência fantasmática, o narrador retira o sentido habitual de determinados objetos, paisagens, situações, pessoas para potencializar sentidos outros que tiram nosso pensamento das convenções de sentido, das conclusões de senso comum, e, por isso, tendem a explorar uma nova perspectiva de olhar para a realidade.

Portanto, o termo fantasmagoria ${ }^{6}$ é utilizado nessas reflexões com base na idéia de que o processo constitui-se na transfiguração de algo inapreensível, nem apropriado, nem perdido; "[...] E assim como o fetiche é, ao mesmo tempo, o sinal de algo e da sua ausência, e deve a tal contradição o próprio estatuto fantasmático, assim o objeto da intenção melancólica é, contemporaneamente, real e irreal, incorporado e perdido, afirmado e negado" (p. 46)

Por isso, se agora voltarmos os olhos para a gravura de Durer, condiz muito bem com a figura alada imóvel aos próprios

\footnotetext{
${ }^{6}$ Os processos fantasmáticos mantêm relação com algumas idéias sobre o fetichismo, que para Marx estava ligado à mercadoria, e que para Lukacs está ligado a reificação, que amplia o conceito de fetiche, ao dilatá-lo para o campo das relações sociais; para como a sociedade percebe a si mesma e o mundo das mercadorias. A ampliação do conceito está naquilo que é subjetivo, na imagem produzida pela sociedade, a respeito dela mesma, e que tenta corresponder ao mundo objetivo. E nesse sentido, podemos pensar nas semelhanças entre a fastamagoria e fetiche.
} 
fantasmas e ao lado da qual está sentado Spiritus phantasticus, representado em forma de anjinho, que os instrumentos da vida ativa fiquem abandonados ao solo, transformando-se em cifra de uma sabedoria enigmática. $\mathrm{O}$ estranhamento inquietante dos objetos mais familiares é o preço pago pelo melancólico às potências que fazem guarda ao inacessível. $O$ anjo que medita não é, segundo uma interpretação já tradicional, o símbolo da impossibilidade da Geometria, e das artes que nela se fundamentam, de alcançar o incorpóreo mundo metafísico, mas pelo contrário, é o emblema da tentativa do homem, no limite de um risco psíquico essencial, de dar corpo aos próprios fantasmas e de tornar predominante, em uma prática artística, aquilo que, do contrário, não poderia ser captado nem conhecido. $O$ compasso, a esfera, a mola, o martelo, a balança, a régua, que a intenção melancólica esvaziou de seu sentido habitual e transformou em emblemas do próprio luto, já não significam nada mais que o espaço que eles tecem para a epifania do inapreensível (AGAMBEN, 2007, p. 55).

Nesse sentido, a narrativa de Os Anéis de Saturno pode ser pensada levando em consideração os apontamentos feitos por Agamben desse processo de criação melancólico-fantasmático. Pensando a partir desses pressupostos, os processos estéticos de W. G Sebald, podem ser relacionados com a tentativa de apreender o inapreensível, da busca pelo entendimento dos absurdos e irracionalismo da guerra, pelo fim inelutável de todas as coisas. 0 próprio narrador comenta sobre o vazio que busca preencher ao iniciar sua caminhada, mas que se mostra incapaz, levando- o à total imobilidade. Desse modo, o próprio narrador de Os Anéis de Saturno pode ser compreendido como uma fanstasmagoria da história pessoal do autor W. G Sebald. Essa (re) elaboração estética das próprias experiências vividas, real ou imaginariamente pelo autor, na voz do narrador-autor é sempre "aspectro", fantasma. Tal quais os fragmentos que "recupera" para mover sentidos que envolvem o tema da guerra e do holocausto, trazendo-os ao texto mesmo que de modo transversal.

Portanto, a melancolia que toma conta do narrador de Os Anéis de Saturno pode ser pensada na dupla faceta entre o sofrimento diante dos vestígios de destruição observados; e o próprio risco melancólico que corre o narrador-autor, ao dar corpo aos próprios fantasmas a partir da matéria artística, numa busca de "captar" o inapreensível, e transfigurá-lo em arte, o que de outro modo não poderia ser conhecido, pois se "[...] a pedra mais pesada da melancolia é a angústia do fim inelutável de nossa natureza, Browne 
[e Sebald] procura [m] entre aquilo que escapou à aniquilação os vestígios da misteriosa capacidade de transfiguração que observou tantas vezes em lagartas e mariposas. (SEBALD, 2010, p. 35)", e assim, Sebald, tal qual, as lagartas e mariposas, deixa vestígios por meio de seus romance, de sua também misteriosa capacidade de transfiguração da linguagem objetiva e do conhecimento em obra de arte.

\section{Considerações finais}

Os Anéis de Saturno é um romance onde o mistério do inapreensível, presente em toda boa arte, fica ressoando como numa espécie de sentido subterrâneo, que nos toca como nos tocam os sons de uma melodia familiar, trazendo em seu material o estranho, que ao mesmo tempo nos compõem; e se diferencia de nós. Fantasmas que somos de nós mesmos, indivíduos sempre incompletos em sua racionalidade e seu potencial de conhecimento. Desse modo, em Anéis de Saturno encontramos latente uma espécie de absurdo que acompanha a história da humanidade e que em muitos momentos parece que se tornou estranhamente a condição de nossa normalidade. Portanto, é uma obra, que mesmo utilizando como material um discurso pleno que não perde certa racionalidade, deixa entrever os absurdos da história européia.

Os Anéis de Saturno provoca atritos no pensamento do leitor, principalmente, por provocar o senso de limitação dos indivíduos que vivem o contexto pós-catástrofes, o que causa a sensação de mal estar e melancolia, movidos pelos sentidos destrutivos do projeto civilizatório europeu. Os personagens de Sebald, de modo geral, são desenraizados, vítimas de diásporas produzidas pela guerra e pelo Shoah. Nesse sentido, a própria estrutura do romance, composto de frases e os parágrafos longos; como também, o caminhar lento e observador empreendido pelo narrador, estão na contramão da velocidade e instantaneidade proposta pelos avanços tecnológicos do século XXI. Contexto onde o cotidiano perpetua a alienação, onde as vidas estão esvaziadas de sentido; e, portanto, onde a preservação da memória é urgente, pois a decadência dela e dos processos de subjetividade 
são riscos da humanidade cair nas mesmas "armadilhas", como foi à banalização do mal. Portanto, é uma romance que constrói uma espécie de anti epopéia ao narrar como a própria racionalidade esteve a serviço da destruição.

\section{REFERÊNCIAS}

AGAMBEN, Giorgio. Estâncias: a palavra e o fantasma na cultura ocidental. Trad. Selvino José Assmann. Belo Horizonte: Editora UFMG, 2007.

SEBALD, W. G. Os anéis de saturno: uma peregrinação inglesa. Trad. José Marcos Macedo. São Paulo: Companhia das Letras, 2010. 